\title{
Isolated jejunal loop hepaticoduodenostomy following excision of type VI-A choledochal cyst
}

\author{
A. D Dharmapala ${ }^{1}$, B.K Dassananyake ${ }^{1}$, P. G Athanospolous ${ }^{2}$, K.B Galketiya ${ }^{1}$, M. Malago $^{2}$ \\ ${ }^{1}$ Department of Surgery, Faculty of Medicine, University of Peradeniya, Sri Lanka \\ ${ }^{2}$ Academic Department of Surgery, University College London/Royal Free NHS trust, Hampstead,London
}

Keywords: Hepaticoduodenostomy; choledochal cyst; MRCP; jejunal loop

\section{Introduction}

Choledochal cyst is a congenital dilatation of the intra hepatic or extra hepatic bile ducts or both. This is classified by Todani classification, which was modified by Alfonso. Depending on the involvement of the biliary tree and the morphological appearance, it is classified into 5 types [1,2] (Figure1). Type I consists of a solitary extrahepatic cyst, type II is an extrahepatic supraduodenal diverticulum, type III is an intraduodenal cyst(choledochocele), type IV consists of both extrahepatic and intrahepatic cysts; and type V consists of multiple intrahepatic cysts (Caroli's disease).

The etiology for the development of this dilatation is still not clearly established but the abnormalous pancreatico biliary junction (APBJ) is so far the most accepted explanation [3]. Due to the APBJ the pancreatic juice is refluxed back into the bile, weakening the wall and resulting in a dilatation of the ducts [4].

The dilated bile ducts allow stasis of bile causing a chronic irritation leading to dysplastic changes in the mucosa and causing cholangio carcinoma [5].

Therefore, the treatment of these cysts consists of complete excision of the cyst and reconstruction with a roux and $y$ hepatico jejunostomy. The simple drainage procedure without excising the cyst will not eliminate the risk of malignancy in these group of patients $[6,7]$.

There are various forms of reconstruction techniques and this is a case report where an isolated jejunal graft with its vascular pedicle is used to reconstruct the bile duct.

\section{Case presentation}

A 21-year-old female presented with repeated attacks of cholangitis and acute pancreatitis. The investigations with an MRCP scan (Figure 2) showed a type IVA choledochal cyst as

Correspondence: Arinda Dharmapala

E-mail: arindad@yahoo.com

(iD https://orcid.org/0000-0002-7414-9241

Received: 08-10-2020 Accepted: 28-03-2021

DOI: http://doi.org/10.4038/sljs.v39i1.8710 the aetiological factor Her cholangitic attacks and pancreatitis were managed successfully and she was scheduled for an elective choledochal cyst excision. The surgery was performed with an upper midline incision.

A careful adhesiolysis and a complete dissection of the cyst were done. It demonstrated that the right anterior, right posterior, left, segment 4 and caudate ducts opening up separately to the hepatic hilum thus confirming the preoperative MRCP scan findings. The distal end was cannulated and an operative cholangiogram was performed to confirm the complete dissection of the cyst right down to the ampulla including the intrapancreatic portion of the common bile duct (Figure 3). Once the extension of the cyst delineated and satisfied with the dissection, the cyst was completely excised with the gallbladder.

A $15 \mathrm{~cm}$ long-isolated jejunal loop with its vascular arcade taken as the conduit to perform the hepaticoduodenostomy. The divided $15 \mathrm{~cm}$ graft was brought up through the transverse mesocolon into the supra colic compartment. The proximal end was then sutured to the opened proximal end of the hepatic duct at the porta hepatis in an end-to-side fashion with a continuous 3/0 Poly dioxone stitch. The distal end of the jejunal graft was anastomosed to the convex or lateral aspect of the second part of the duodenum (D2) similarly with $3 / 0$ poydiaxone. The graft was kept in an isoperistaltic manner (Figure 4). The graft vascularity was good and there was no bile leak from the anastomoses. The proximal and distal ends of the jejunum were anastomosed with a $3 / 0$ polydioxanone stitch in a double-layered fashion to keep the continuity of the small intestine. The abdomen was closed by routine closure leaving a size FR 24 drain in the right subhepatic space. A single dose of teicoplanin, gentamycin and metronidazole was given as prophylactic antibiotics.

The patient had an uneventful recovery. She had a follow-up MRCP 6 months and 1 year later which did not show any evidence of anastomotic strictures. She is asymptomatic two years following surgery. The histology of the cyst wall showed chronic inflammatory changes only and there was no evidence of metaplasia or malignancy 


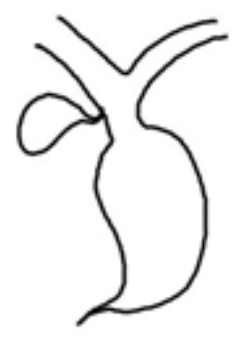

Type I

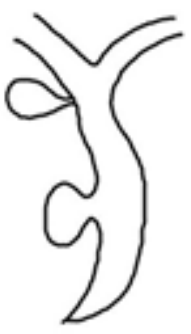

Type II

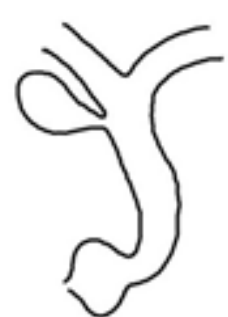

Type III

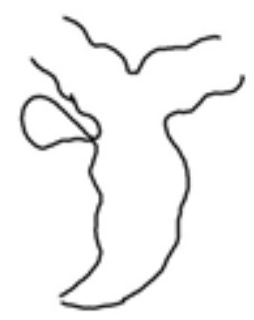

Type IV A

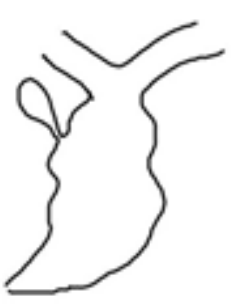

Type IV B

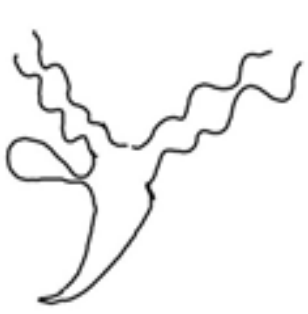

Type V

\section{(Caroli's Disease)}

Figure1. Appearance of 5 types and the subtypes of biliary tree depending on the involvement and the morphological appearance

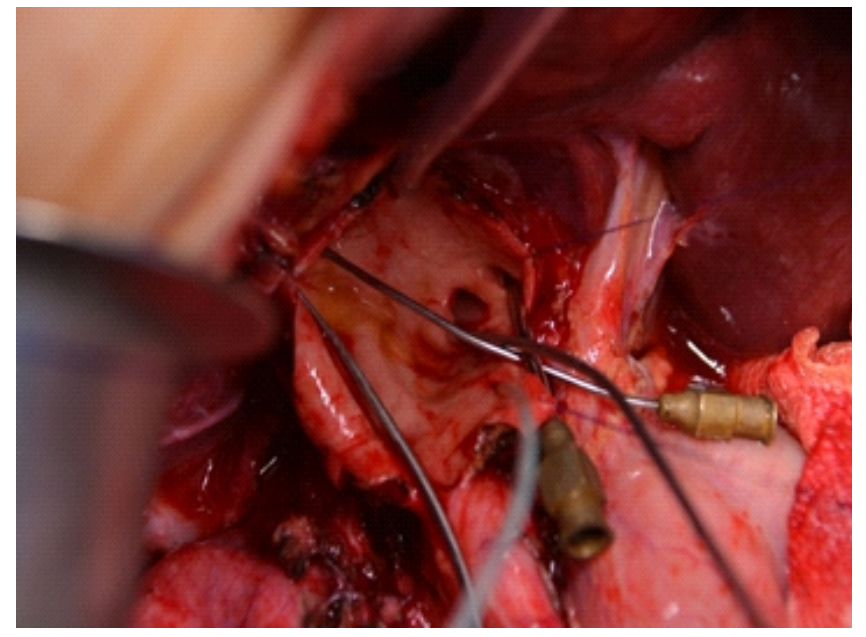

Figure 2. Demonstrate the hilum with the opening of the ducts

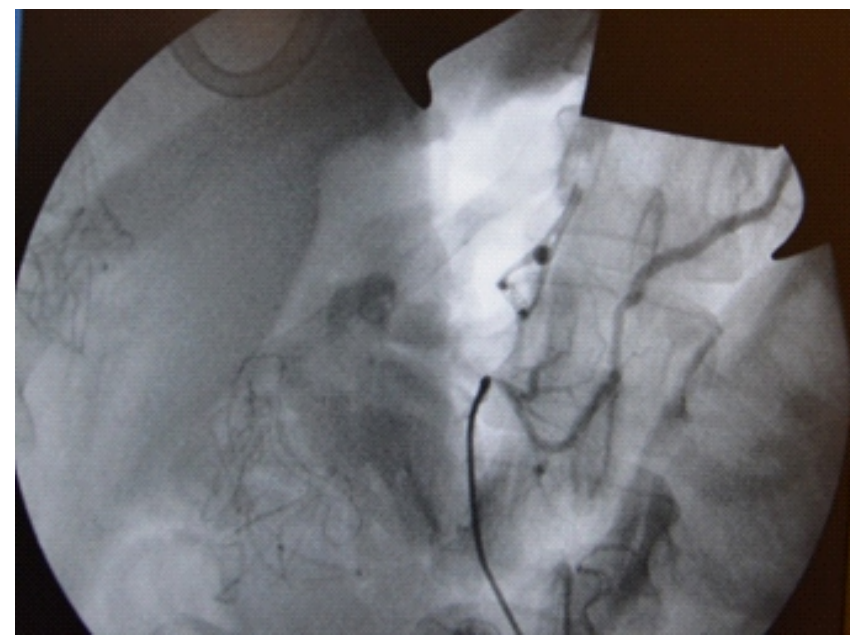

Figure 3. The intra operative cholangiogram demonstrating the distal end of the bileduct and the cannula tip lies just at the junction of the CBD to the PD. The contrast can be seeing going in to the PD.


Figure1. The hepatico jejunostomy and the preparation for the hepatico duodenostomy 


\section{Discussion}

The management of type IV-A choledochal cyst involves the complete excision of all the dilated ducts as much as possible. Some advocate dissection into the parenchyma to remove all dilated intrahepatic ducts or remove the segment of the liver which is involved. Since it was bilobar disease we were unable to proceed further. The further dissection into the liver would have done more harm than a benefit.

The wide opening of the hilum and creating a wider anastomosis is essential in preventing anastomotic strictures, which is a major concern in hepaticojejunostomy. This is also a key factor in preventing bile stasis and recurrent cholangitis. In this patient also we were able to create a wider anastomosis and it demonstrated that after a follow up of two years, that there is good drainage of bile without any stasis or cholangitis. The hepaticoduodenostomy which is commonly done in the paediatric group has shown some increased risk of cholangitis and has gone out of favour. This is usually direct anastomosis of the duodenum into the liver hilum. But the chances are minimal for translocation of bacteria when there is an interposition graft and the possibility of recurrent cholangitis is very rare [9].

Hepticoduodenostomy is more physiological and this gives easy endoscopic access in follow up of these patients. Stricture formation is one of the commonest and difficult complications to manage. Endoscopic access is advantageous in this situation as a therapeutic option. The endoscopic access gives an additional advantage of a more detailed inspection with direct visualization by cholangiospcopic usage.

Other advantage of endoscopic surveillance is that biopsies can be taken from suspicious areas. These factors favour the jejunal interposition heaptico duodenostomy than a roux -en - Y reconstruction.

The adequate length of the interposition graft is also important in preventing ascending cholangitis. The duodenogastric reflux should be minimal in the interposition hepatico duodenostomy as there is minimal disruption of the pylorus and the duodenum [10].
It is demonstrated that jejunal interposition hepaticoduodenostomy will be a more physiological reconstruction following excision of choledochal cyst than other commonly used reconstruction methods. Moreover, this gives the additional benefit of having endoscopic access for close monitoring as well as in managing post-operative complications. Therefore, this can be recommended as a safe procedure in managing patients with choledochal cysts who require intense and long term follow up.

All authors disclose no conflict of interest. The study was conducted in accordance with the ethical standards of the relevant institutional or national ethics committee and the Helsinki Declaration of 1975, as revised in 2000 .

\section{References}

1. Todani T, Watanabe Y, Narusue M, Tabuchi K, Okajima K. Congenital bile duct cysts. The American Journal of Surgery. 1977;134(2):263-9. https://doi.org/10.1016/0002-9610(77)90359-2

2. Alonso-Lej F, editor Congenital choledochal cyst, with a report of two and analysis of 94 cases. Int Abstr Surg; 1959.

3. Babbitt D, editor Congenital choledochal cysts: new etiological concept based on anomalous relationships of the common bile duct and pancreatic bulb. Annales de radiologie; 1969.

4. Kimura K, Ohto M, Ono T, Tsuchiya Y, Saisho H, Kawamura K, et al. Congenital cystic dilatation of the common bile duct: relationship to anomalous pancreaticobiliary ductal union. American Journal of Roentgenology. 1977;128(4):571-7. https://doi.org/10.2214/ajr.128.4.571

5. Hasumi A, Matsui H, Sugioka A, Uyama I, Komori Y, Fujita J, et al. Precancerous conditions of biliary tract cancer in patients with pancreaticobiliary maljunction: reappraisal of nationwide survey in Japan. Journal of hepato-biliary-pancreatic surgery. 2000;7(6):551-5.https://doi.org/10.1007/s005340070003

7. Ohashi T, Wakai T, Kubota M, Matsuda Y, Arai Y, Ohyama T, et al. Risk of subsequent biliary malignancy in patients undergoing cyst excision for congenital choledochal cysts. Journal of gastroenterology and hepatology. 2013;28(2):243-7. https://doi.org/10.1111/j.1440-1746.2012.07260.x

8. Shimotakahara A, Yamataka A, Yanai T, Kobayashi H, Okazaki T, Lane GJ, et al. Roux-en-Y hepaticojejunostomy or hepaticoduodenostomy for biliary reconstruction during the surgical treatment of choledochal cyst: which is better? Pediatric surgery international. 2005;21(1):5-7.

https://doi.org/10.1007/s00383-004-1252-1 
9. Chijiiwa K, Komura M, \& Kameoka, N. Postoperative follow-up of patients with type IVA choledochal cysts after excision of extrahepatic cyst. Journal of the American College of Surgeons. 1994; 179(6):641-645
10.Xia, Hong-Tian, Tao Yang, Bin Liang, Jian-Ping Zeng, and JiaHong Dong. Treatment and Outcomes of Adults with Remnant Intrapancreatic Choledochal Cysts. Surgery 2016; 159(2):41825. https://doi.org/10.1016/j.surg.2015.04.042

\section{Learning Points:}

- Isolated jejunal loop hepaticoduodenostomy following excision of type VI-A choledochal cyst is a more physiological reconstruction.

- The ability for endoscopic access is the main advantage in dealing with complications and long term follow up.

- It is technically not difficult to perform 